\title{
Hypertension and multiple arterial changes in a child with Klippel Trenaunay syndrome
}

\section{Klippel-Trenaunay sendromlu bir çocukta hipertansiyon ve multipl arteriyel değişiklikler}

Meral Torun Bayram¹, Önder Yavaşcan², Aytaç Gülcü ${ }^{3}$, Nejat Aksu², Salih Kavukçu ${ }^{1}$, Alper Soylu ${ }^{1}$

\begin{abstract}
Klippel-Trenaunay syndrome (KTS) is an inherited disorder which essentially affects the venous system. Arterial malformations accompanying venous pathologies are extremely rare. We report a 10 -year-old boy of KTS patient presented with hypertension and renal atrophy who have also multiple arterial (renal, pulmonary and internal carotid) pathologic features. J Clin Exp Invest 2014; 5 (4): 610-613
\end{abstract}

Key words: Hypertension, arterial changes, Klippel-Trenaunay syndrome

\section{INTRODUCTION}

Klippel-Trenaunay syndrome (KTS), first described by Klippel and Trenaunay in 1900 [1], is a rare congenital syndrome characterized by the combination of localized vascular nevus, congenital or early infantile varicosities on the body part, and hypertrophy of tissues [2]. It is also referred to as Angioosteohypertrophy syndrome.

In this syndrome, clinical findings are generally associated with venous and capillary pathologies and local and systemic complications such as hypertension can be observed [2-5]. One case with arterial (iliac and femoral) stenosis and two cases with hypertension relevant to KTS have been described so far $[3,6]$. We report a 10-year-old boy of KTS having thin calibrated pulmonary and internal carotid artery together with renal artery stenosis presented with hypertension and renal atrophy.

\section{ÖZET}

Klippel-Trenaunay sendromu (KTS) özellikle venöz sistemi etkileyen kalıtsal bir hastalıktır. Venöz patolojilere eşlik eden arteriyel malformasyonlar oldukça nadirdir. Biz burada hipertansiyon ve renal atrofi nedeni ile başvuran, multipl arteriyel (renal, pulmoner ve internal karotid) patolojik özelliklere sahip KTS'lu 10 yaşında bir erkek hastayı sunduk.

Anahtar kelimeler: Hipertansiyon, arteriyel değişiklikler, Klippel-Trenaunay sendromu

\section{CASE REPORT}

A 10- year-old male patient presented to our pediatric nephrology clinic from another center for further evaluation of hypertension. Past medical history includes recurrent bronchiolitis, patent ductus arteriosus which was embolized with endovascular occluder device, and hypertension determined 3 years ago at school screening. At that time, laboratory tests covering plasma renin activity $(20 \mathrm{ng} /$ $\mathrm{ml}, \mathrm{N}=0.5-5)$ and urine protein $\left(11 \mathrm{mg} / \mathrm{m}^{2} / \mathrm{h}, \mathrm{n}=0-4\right)$ levels were reported to be high. Blood pressure load (BPL) on ambulatory blood pressure monitoring (ABPM) was high and right renal atrophy was demonstrated on dimercaptosuccinic acid scintigraphy. Computed tomography (CT) angiography findings demonstrated bilateral accessory renal arteries, right renal artery stenosis and occlusion in right renal accessory artery proximal segment

${ }^{1}$ Dokuz Eylül University, Medical Faculty, Department of Pediatrics, Izmir, Turkey
2 Tepecik Training and Research Hospital, Department of Pediatrics, Izmir, Turkey
${ }^{3}$ Dokuz Eylül University, Medical Faculty, Department of Radiology, Izmir, Turkey

Correspondence: Meral Bayram,

Dokuz Eylül University Medical Faculty, Dept. Pediatric Nephrology Izmir, Turkey Email: meralt.bayram@yahoo.com.tr

Received: 24.09.2014, Accepted: 19.11.2014

Copyright (C) JCEI / Journal of Clinical and Experimental Investigations 2014, All rights reserved 
(Figure 1). Other examinations (renal function tests, echocardiography, fundus examination, and renovascular/extremity doppler ultrasonography) were normal. Physical examination revealed hypertrophy and varicose veins in the right lower extremity and operation scar in the 4 and 5 the fingers of right hand. His arterial blood pressure was 110/70 $\mathrm{mmHg}$ (under beta blocker, angiotensin converting enzyme inhibitor, and calcium canal blocker treatment) and his plasma creatinine level was $0.5 \mathrm{mg} /$ dl. The dipstick urine test was negative for proteinuria. Increased BPL on ABPM and renal artery stenosis on CT angiography lead us to consider renovascular hypertension associated with KTS. Renal angiography demonstrated stenotic segments in the right renal artery, upper pole segmental branch of the left renal artery and the accessory left renal artery. Also proximal segment of right accessory renal artery was occluded (Figure 2). String of beads appearance relevant to fibromuscular dysplasia was observed in the right main renal artery. Stenotic renal artery segments were dilated to normal calibration with balloon angioplasty. In the follow-up, antihypertensive treatment was reduced to a single antihypertensive drug (propranolol) due to achieved normal blood pressure course. Cranial magnetic resonance imaging (MRI) and angiography (MRA) were performed because of headache. MRI was normal, while MRA revealed a thin calibrated right internal carotid artery although no intracranial variation such as isolated hemisphere existed (Figure 3). Thoracic CT was performed due to recurrent acute bronchiolitis which showed a thin calibrated left pulmonary artery (Figure 4). Although their calibration are thinner relatively to the contralateral site, right internal carotid artery and left pulmonary artery were not hypoplasic. In clinical follow-up, restenosis and /or arteriovenous fistula (AVF) were suspected due to again detection of high BPL (all day systolic $\mathrm{BPL}=50 \%$ ). Renal ultrasonography showed increase in the echogenicity and decrease in the size of right kidney, while renovascular and extremity doppler ultrasonography and angiography were within normal limits (no restenosis or AVF). The BPL was considered to be associated with renal atrophy and/or contour irregularity. Therapy with beta-blocker (propranolol), calcium canal blocker (nifedipine) and aspirin was carried out at that moment.

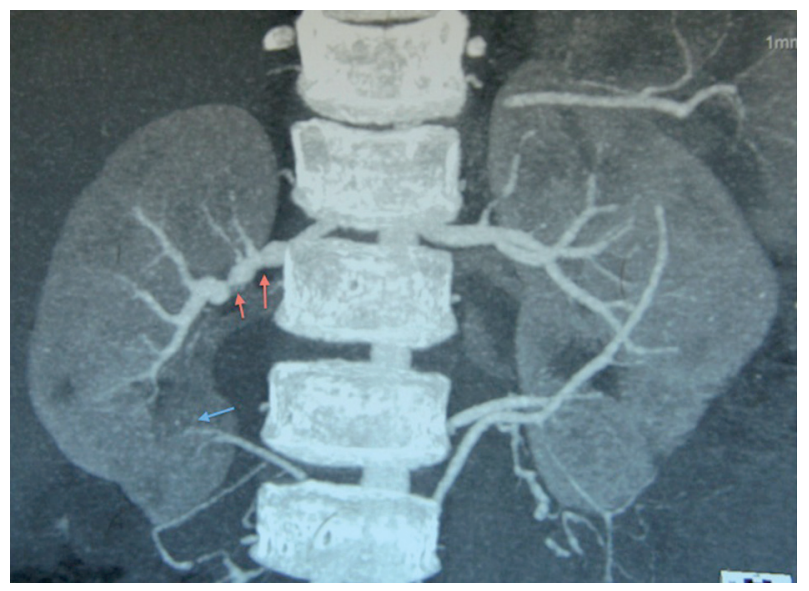

Figure 1. CT angiography findings showing bilateral accessory renal arteries, right renal artery stenosis (red arrows) and occlusion in right renal accessory artery proximal segment (blue arrow).

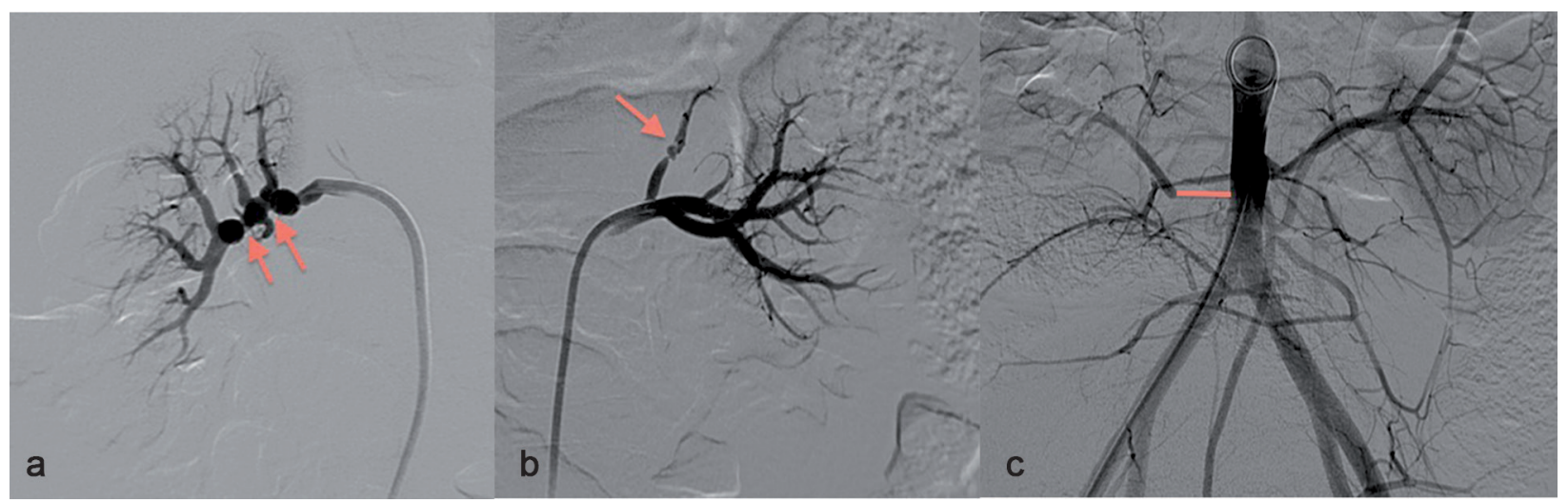

Figure 2. a String of beads appearance was seen in the selective right renal angiogram. b Selective left renal angiogram showing stenotic segment in the upper pole segmenter branch. c Straight red line predicts the localization of occluded right renal lower pole accessory artery, the distal segment of the artery is filling via the collaterals. 


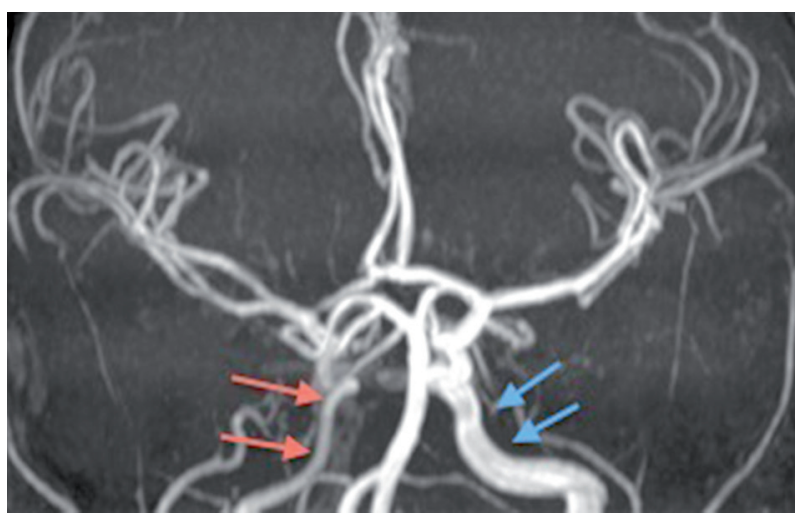

Figure 3. Red arrows indicating thin calibrated right internal carotid artery in comparison to the normal left internal carotid artery indicated by blue arrows.

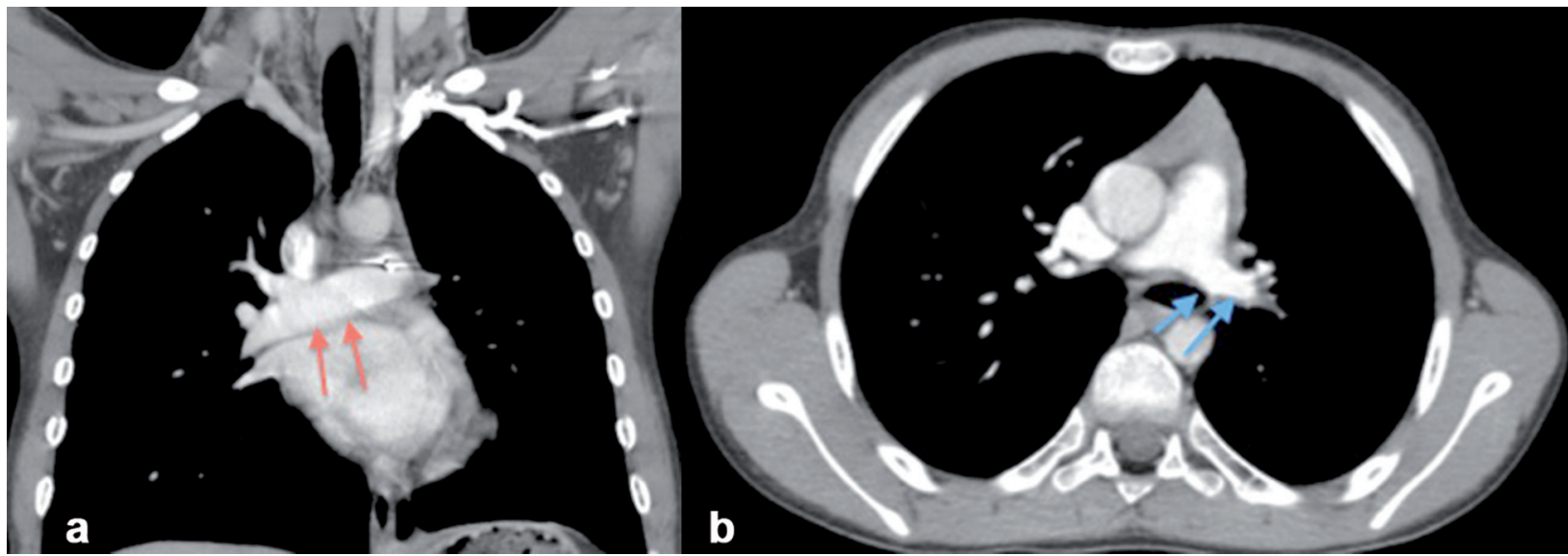

Figure 4. Thoracic CT axial slices and coronal MPR's demonstrate thin calibrated left pulmonary arterial system (blue arrows) in comparison to right pulmonary arterial system (red arrows)

\section{DISCUSSION}

KTS is characterized by two major features, as congenital vascular (capillary, venous, arteriovenous, lymphatic) malformation and disturbed growth (soft or bone in the length or girth) which are diagnostic. In KTS, also there may be nonobligatory and nonessential symptoms. These symptoms are limb anomalies (i.e. syndactyly), positional limb defects, and autonomous dysfunction. If the most recent diagnostic criteria of KTS are considered [2], diagnosis of our patients (soft tissue hypertrophy associated with venous malformations and syndactyly) is sufficiently for typical KTS.

Local complications such as ulceration, cellulitis, thrombophlebitis, thrombosis, emboli, hemorrhages, edema, pain, and systemic complications such as neurovascular anomalies, pulmonary vein varicosities, pleuro-pericardial effusions, pulmonary embolism, colorectal and urinary tract hemorrhage, and hypertension are described in patients with KTS [2-5,7]. To cause and result relationship of the complications such as renovascular hypertension in various parts of the body in patient with KTS, Jolobe reported following: 1) coexisting ipsilateral angiomatosis should be exemplified by neurovascular anomaly such as cerebral AVF with corresponding symptomatology, 2) intrathoracic manifestations such as pulmonary vein varicosities and lymphangiectatic sclerosis giving rise to pleural and pericardial effusions, and an increased liability to pulmonary embolism, 3) abdominal viscera affected by ipsilateral angiomatosis include the colon, and urinary tract, with consequent rectal bleeding, hematuria, and renovascular hypertension [3].

Two cases reporting hypertension with concomitant KTS were found in the literature. In one of these patients, an isotope renogram showed ipsilateral renal atrophy and ipsilateral superficial 'blush' finding clarified with superficial shunting of blood supply away from the affected kidney. However, in the case report, there were no clearly relevant information with renal artery stenosis, treatment to hypertension and the course of hypertension. In our 
patient, there were findings such as renal atrophy and shunting, and hypertension associated with renal artery stenosis. However, BPL recurred after balloon angioplasty. Therefore, we repeated renovascular and extremity doppler ultrasonography and angiography examinations, but not established any restenosis. Thus, the BPL was considered to be associated with renal atrophy.

Patients with KTS have a complex set of anomalies that includes cutaneous capillary malformation (usually on an affected limb), abnormal development of the deep and superficial veins, and limb asymmetry, usually enlargement. Mixed vascular malformations may be present and include capillary, venous, arterial and lymphatic systems [8]. However, arterial malformations are extremely limited, including stenosis, aplasia and aneurysm [9-12]. In literature, while there are few cases with arterial aneurysms (brachial, renal, multiple) accompanying KTS, but there is only one patient (7-year-old boy) with arterial stenosis concomitant KTS, who had iliac and femoral artery stenosis at different levels [6]. However, there is no patient with thin calibrated pulmonary and internal carotid artery together with renal artery stenosis. Our patient is the first patient having these features.

While pathogenesis of KTS is not well understood yet, artery involvement in a patient with KTS is rather difficult to explain. However, several hypotheses have been published in pathogenesis of KTS. Some of these hypotheses are disturbed vasculogenesis, generalized mesodermal defects, paradominant inheritance, a dominant lethal gene surviving by mosaicism [2]. At the same time, these hypotheses, especially disturbed vasculogenesis, may explain the involvement of arteries in KTS.

In summary, this case illustrates the co-existence of multiple arterial changes and/or stenosis with KTS. Therefore, KTS should not be regarded as just another case of varicose veins and should be included in differential diagnosis of patients with multiple arterial stenosis such as fibromuscular dysplasia, Ehlers-Danlos syndrome, Williams' syndrome, type 1 neurofibromatosis, Takayasu arteritis [13] and other arterial malformation syndromes.

\section{REFERENCES}

1. Klippel M, Trenaunay P. Du noevus variquex osteohypertrophique. Arch Gen Med (Paris) 1900;185:641672.

2. Oduber CE, van der Horst CM, Hennekam RC. KlippelTrenaunay syndrome diagnostic criteria and hypothesis on etiology. Ann Plast Surg 2008;60:217-223.

3. Jolobe OM. Klippel-Trenaunay syndrome. Postgrad Med J 1996;72:347-348.

4. Samuel M, Spitz L. Klippel-Trenaunay syndrome: clinical features, complications, and management in children. Br J Surg 1995;82:757-762.

5. Lee A, Driscoll D, Gloviczki $P$, et al. Evaluation and management of pain in patients with Klippel-Trenaunay syndrome: a review. Pediatrics 2005;115:744749.

6. Uğurlucan M, Yerebakan C, Alpagut U, et al. KlippelTrenaunay-Weber syndrome. Wien Med Wochenschr 2008;158:402-404.

7. Proesmans W, Van Damme B, Marchal G, et al. KlippelTrenaunay syndrome with systemic hypertension and chronic renal failure. Ann Pediatr (Paris) 1982;29:671.

8. Berry SA, Peterson C, Mize W, et al. Klippel-Trenaunay syndrome. Am J Med Genet 1998;79:319-326.

9. Bartels C, Claeys L, Ktenidis K, et al. Weber syndrome associated with a brachial artery aneurysm. A case report. Angiology 1995;46:1039-1042.

10. Sharma S. Multifocal intradural spinal AVF and renal artery aneurysms in a case of Klippel Trenaunay Syndrome (KTS). J Neuroimaging 2010;20:386-389.

11. Pourhassan S, Grotemeyer D, Klar V, et al. The Klippel-Trenaunay syndrome associated with multiple visceral arteries aneurysms. Vasa 2007;36:124-129.

12. Goldstein SJ, Lee $C$, Young AB, et al. Aplasia of the cervical internal carotid artery and malformation of the circle of Willis associated with Klippel-Trenaunay syndrome. Case report. J Neurosurg 1984;61:786-789.

13. Plouin PF, Perdu J, La Batide-Alanore A, et al. Fibromuscular dysplasia. Orphanet J Rare Dis 2007;2:28. 